\title{
Gender Differences in Adolescent's Health: the Effect of Coping Mechanism
}

\author{
Farzana Parveen ${ }^{1}$, Sarah Javed ${ }^{2}$
}

\section{ABSTRACT}

Introduction: Previous studies have suggested that male and female experience different types and severities of physical and psychological health symptoms. This study examined whether in the case of adolescents gender differences in physical and psychological health symptoms could actually be the result of differences in coping mechanism. Various factors have an influence on which coping strategies are mobilized under specific circumstances like age and gender. The present paper focuses on the interrelationships between the ways of coping and some healthrelated variables in adolescence. Objectives: (i) To find out gender differences affecting physical and psychological health symptoms. (ii)To find out gender differences affecting coping styles.(iii) To ascertain the relationship between coping styles and both physical and psychological health symptoms, in both male and female adolescents. Methods: The participants of the present study comprised of 100 adolescents male 50 and female 50 and they were from senior secondary schools and graduate schools recruited from Aligarh. They are adolescents and their age ranged from 13 to 18 years. Measures: Brief Cope Scale was developed by (Carver. 1997). The Brief Cope is a Likert type questionnaire that contains 14 strategies although the Brief COPE contains 28 items. WHO-QOL Scale: World Health Organization Quality of Life assessment, the WHOQOL-100 is a cross-culturally valid assessment of well-being. Assessment is operationalized through 100 items representing 25 facets organized in six domains. Result and Conclusion The results of this study suggest that doctors, school counselors and family therapists may want to take gender differences in coping styles into account when seeing adolescent patients for physical or psychological health symptoms, and find ways to help the adolescents cope more effectively with their stressors.

Keywords: Gender, Physical and Psychological health

Gender has been defined as a cultural construct which distinguishes the roles, behavior, mental and emotional characteristics between males and females (Keller,1991). In addition, Shettima (1996) defined gender as roles and actions ascribed to women and men so as to distinguish who they are, what is expected of them by the society and how they related to each other for meaningful coexistence. Pertinent to the gender differences in stress experiences, NolenHoeksema (1990) and Weissman et al. (1996) noted that across many nations, cultures and ethnicities, females are about twice as likely as males to develop depression or any other physical

\footnotetext{
${ }^{1}$ Research Scholar in Psychology, Department of Psychology, Aligarh Muslim University, Aligarh

${ }^{2}$ Research Scholar In Clinical Psychology, Department of Psychiatry, Jawahar Laal Nehru Medical College , Aligarh Muslim University, Aligarh

(C) 2015 I F Parveen, S Javed; licensee IJIP. This is an Open Access Research distributed under the terms of the Creative Commons Attribution License (http://creativecommons.org/licenses/by/2.0), which permits unrestricted use, distribution, and reproduction in any Medium, provided the original work is properly cited.
} 
or psychological symptoms which is linked to anxiety or any other psychological or physical problems. They reported further that female face a number of chronic burdens in everyday life as a result of their social status and roles relative to males, and these strains could contribute to their higher rates of psychological issues.

In education system, adolescents are who those receiving education in junior high schools, senior high schools, colleges or universities. Due to fast physical changes and mental development at this stage, students may sometimes experience incompatibility of their mental development with their physical changes or with the social environment and thus suffer from problems arising from inadequate adaptations. These problems may further cause psychological troubles and even induce deviant behaviors. Pinel (2003 ) defines stress as a physiological response to perceived threat. It therefore has negative effects on life's pressures and events (Benson and Stuart, 1992) and can generally be viewed as a set of neurological and physiological reactions that serve as an adaptive function (Franken, 1994). Holmes and Rahe (1967) indicated that any life change that requires numerous readjustments can be perceived as stressful. So it is essential for adolescents to develop effective strategies in order to cope with these new stressors for positive growth and development (Werner, 1989) Stress levels among college students are higher than those of people at any other stage of life, Stress occurs when pressure exceeds beyond its perceived ability to cope. Stress is the body's reaction to a change that requires a physical, mental or emotional adjustment or response.

\section{COPING STRATEGIES:}

The concept of coping is based on three theoretical components namely: physiological, cognitive and learned. Physiologically, the body's systems have their own ways of coping with distressing events. The term coping refers to adaptively changing cognitive and behavioral efforts to manage psychological stress. It identifies the ways in which people handle and manage stressful situations. It involves managing troublesome circumstances, expelling effort to solve life's problems, and seeking to master or deal with problematic situations. On the other hand, coping strategies include problem-focused coping, emotion-focused coping and seeking social support (Kohlman; Weidener; Dotzauer \& Burns, 1997).

Coping strategies are known to influence an individuals' experience of stress. For most students, managing stress during college can be extremely challenging. However, learning how to manage stress may help students cope with every day social and academic pressures, and thus have a better college experience. ). Coping strategies have been defined by Lazarus and Folkman (1984) as a set of behavioral and cognitive responses that are designed to minimize the demands of a stressful situation. In recent years, research has suggested that the type of coping strategy employed by an individual affects not only mental health, but also physical well-being (Wheaton, 1985; Piko, 2001). Some Studies have examined coping strategies of adolescents with the stresses of undergraduate education have generally identified the use of alcohol as a coping strategy (Guthrie et al., 1995; Campbell et al., 1998), but some studies have reported the 
use of other substances such as tobacco and drugs (Miller and Surtees, 1991; Ashton and Kamali, 1995). A study from Pakistan reported that sports, music and hanging out with friends were common coping strategies (Shaikh et al., 2004). Being able to manage responsibilities, problems, or difficulties in a calm and thoughtful manner is one way of coping.

\section{OBJECTIVES}

The present study had fallowing objectives-

- To find out gender differences affecting physical and psychological health symptoms.

- To find out gender differences affecting coping styles.

- To ascertain the relationship between coping styles and both physical and psychological health symptoms, in both male and female adolescents.

\section{MATERIAL \& METHODS}

Participants / Sample: The participants of the present study comprised of 100 adolescents male 50 and female 50 and they were from senior secondary schools and graduate schools recruited from Aligarh. They are adolescents and their age ranged from 13 to 18 years.

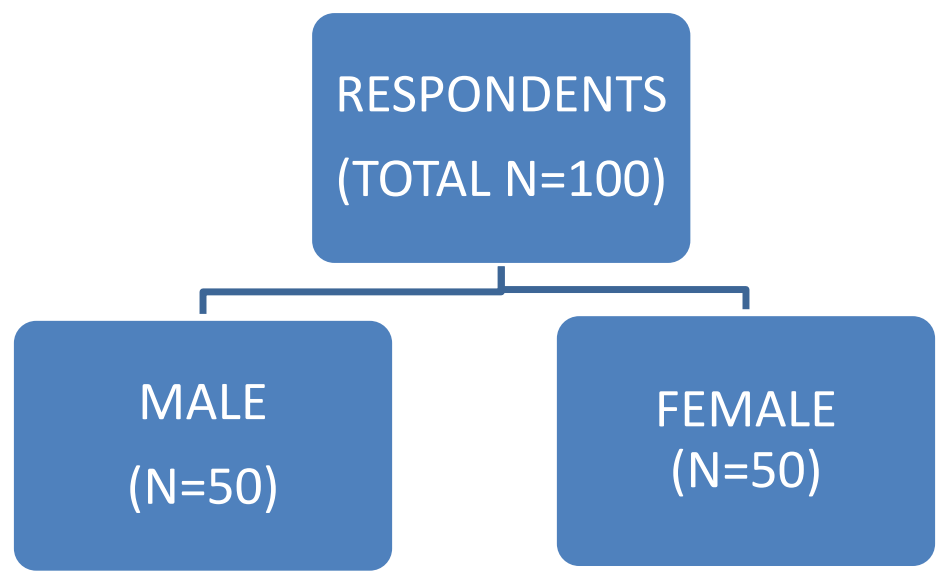

\section{Tools Used:}

BRIEF COPE SCALE: The Brief COPE is a Likert type questionnaire that contains 14 strategies (e.g., use of alcohol/drugs to cope, seeking emotional support, giving up, etc.). Although the Brief COPE contains 28 items, we selected one item from each of the 14 strategies based on data analysis of our previous research (Pritchard \& Wilson, 2003). Students responded to how they would deal with a stressful event on a 4-point scale ranging from 1 (I wouldn't do this at all) to 4 (I would do this a lot). This measure has been tested on a variety of populations (Pritchard \& McIntosh, 2003), and has been validated and shown to be reliable (Carver, 1997; Perczek, Carver, Price, \& Pozo-Kaderman, 2000). Moreover, it has been successfully used with adolescents (Townsend, 2002). 
WHOQOL SCALE: The WHOQOL-100 quality of life assessment was developed by the WHOQOL Group fifteen international field centers, simultaneously, in an attempt to develop a quality of life assessment that would be applicable cross-culturally World Health Organization Quality of Life assessment, the WHOQOL-100 is a cross-culturally valid assessment of wellbeing. The WHOQOL -BREF contains a total of 26 questions. To provide a broad and comprehensive assessment one item for each of the 24 facets contained in the WHOQOL-100 has been included. Two items from the overall Quality of life and General Health facets have been included.

\section{RESULT}

The present study was conducted to examine the individual differences in adolescents physical and psychological health symptoms, and gender differences in coping mechanism used by individual.

\section{Gender differences in physical and psychological health symptoms:}

We first examined gender differences in physical illness and psychological problems in our population, which is presented in table no-1 for their differences we used independent sample ttest which revealed significant gender differences in physical health and psychological health symptoms $(\mathrm{N}=100)$, males were found to have more physical health symptoms than females and this differences was found to be significant $(\mathrm{t}=2.302, \mathrm{p}=<.05)$ on the other hand males were again found to have more psychological health symptoms than female and this differences was again found to be of significant level $(t=.558, \mathrm{p}=.05)$ and not due to chance.

\section{Table 1 Showing Mean Of PHH \& PSH Symptoms by Gender}

\begin{tabular}{|lc|l|l|l|l|}
\hline \multicolumn{2}{|c|}{ DOMAIN } & N & MEAN & SD & T \\
\hline \multirow{2}{*}{ PHH } & MALE & 50 & 8.1000 & 1.21638 & 2.302 \\
& FEMALE & 50 & 7.5600 & 1.12776 & 2.302 \\
\hline \multirow{2}{*}{ PSH } & MALE & 50 & 9.1200 & 1.46580 & .558 \\
& & & & & \\
& FEMALE & 50 & 8.9600 & 1.39913 & .558 \\
\hline
\end{tabular}

${ }^{*} \mathrm{p}<.05, \mathrm{PHH}=$ Physical health, $\mathrm{PSH}=$ psychological health.

\section{Gender differences in coping styles:}

The second objective of this study is to examine the coping style of the individual which is presented in table no-2, t-test was used to reveal significant differences in coping technique used by the individuals and this differences was significant $(\mathrm{t}=.52, \mathrm{p}=<0.05)$ and to explain which coping strategies was used more we moved to the next objective of our study. 
Table 2 Means and Standard Deviation of Coping Style by Gender

\begin{tabular}{|l|l|l|l|l|}
\hline DOMAINS & N & MEAN & SD & T \\
\hline Male & 50 & 50.200 & 10.5366 & .750 \\
Coping & & & & \\
Female & 50 & 48.460 & 12.5847 & .750 \\
\hline
\end{tabular}

${ }^{*} \mathrm{p}<.05$, Coping Style

\section{Gender differences in type of coping mechanism used by individuals:}

One of the objective of this study as to know which type of coping mechanism is being used by the individuals which is represented in table no-3. On the basis of items in the Brief Cope Inventory coping was broadly classified into two groups emotion focused coping and problem focused coping. T-test was used to examine the differences: Result of t-test revealed significant gender differences in emotion focused coping and problem focused coping $(\mathrm{N}=100)$, Males were found to use more emotion focused strategies than females $(t=1.22, p=0.05)$ and on the other hand females were found to use more problem focused coping than males $(\mathrm{t}=.82, \mathrm{p}=0.05)$, the differences not due to chance.

Table 3 Correlations between Coping Styles and Symptoms

\begin{tabular}{|l|l|l|l|l|}
\hline Coping Style & $\mathrm{N}$ & Mean & SD & T \\
\hline $\begin{array}{l}\text { Problem Focused } \\
\text { coping }\end{array}$ & 50 & 38.40 & 8.87 & 1.22 \\
$\begin{array}{l}\text { Emotion Focused } \\
\text { coping }\end{array}$ & 50 & 35.98 & 10.77 & \\
& 50 & 11.80 & 2.72 & .82 \\
\hline
\end{tabular}

${ }^{*} \mathrm{p}<.05$, PFC $=$ Problem Focused Coping, EFC= Emotion Focused Coping

\section{Relationship between coping style and physical and psychological health symptoms:}

Last objective of our study was to examine the relationship between coping style \& physical and psychological health symptoms. Table no-4 shows that there is a negative relation between psychological health symptoms \& emotion focused coping which indicate that as psychological health symptoms increases emotion focused coping decreases and as psychological health symptoms decreases emotion focused coping increases on the other hand there exist a positive 
relation between psychological health and problem focused coping than both these relationship are not significant. Likewise there is a negative relationship between physical health symptoms with emotion focused coping \& problem focused coping, which means as physical health symptoms increases emotion focused coping decreases and vice- versa. Again the differences found are not significant.

Table 4

\begin{tabular}{|l|lr|l|}
\hline Health symptoms & $\begin{array}{l}\text { Emotion focused } \\
\text { coping }\end{array}$ & $\begin{array}{l}\text { Problem focused } \\
\text { coping }\end{array}$ \\
\hline $\begin{array}{l}\text { Psychological health } \\
\text { symptoms }\end{array}$ & -.065 & .090 \\
\hline Physical health symptoms & -.169 & -.062 \\
\hline
\end{tabular}

\section{DISCUSSION}

The main goal of the present study was to compare gender differences in physical and psychological health symptoms in both male and female adolescents. We had hypothesized that females would report more negative physical and psychological health symptoms. And the second aim was to investigate gender differences in coping mechanism. Based on previous studies, we had hypothesized that females would utilize more emotion-focused coping styles as compare to males because males would utilize more problem-focused coping mechanism. The last objective of this study was to ascertain the relationship between coping styles and both physical and psychological health symptoms in male and female adolescents. We had hypothesized that the relationships between coping styles and physical and psychological health symptoms would differ significantly for male and female adolescents.

\section{Gender differences in physical and psychological health symptoms:}

Similar to previous research, we found that females reported more physical health symptoms, such as headaches, body pain, than do adolescent males (Linet et al., 1989; Stang \& Osterhaus, 1993). In addition, adolescent females reported more psychological symptoms, such as tension and depression, than did adolescent males (Cauce et al., 2000; Myers et al., 1984; Nolen Hoeksema, 1991). Interestingly, in addition to reporting more negative psychological symptoms females in our study also reported more of the positive health symptom "vigor"' than did males. However, contrary to some previous research (Myers et al., 1984; Nolen-Hoeksema, 1991), females in our study actually reported more anger than males. This difference could partially be explained by examining the types of angry behaviour analysed. For example, Tamres et al. (2002) performed a comprehensive meta-analysis of recent coping research. Results from this analysis indicated that venting was measured in some studies as aggressive behaviour (i.e., anger) while in other studies it was more passive in nature (i.e., crying). Hence, definitions of 
angry coping behavior are not always clearly delineated and this may lead to varying interpretations of data (Tamres et al., 2002)

\section{Gender differences in coping mechanism:}

Similar to previous studies (Felsten, 1998; Houtman, 1990; Mullis \& Chapman, 2000; Porter \& Stone, 1995; Schaffer \& Pritchard, 2003), we found gender differences in coping mechanism. Research (Ptacek et al., 1994) has traditionally found that adolescent females used emotionoriented coping strategies more often than males who typically tend to be more problem-oriented (Stone \& Neale, 1984). In contrast, the females in our study were more likely to use both emotion-focused and problem-solving strategies than adolescent males. This supports the findings reported by Piko (2001) with Hungarian adolescents who found that while girls used both passive and emotion-oriented ways of coping more often than boys, they also turned to problem-solving strategies as well. Moreover, the meta-analysis conducted by Tamres et al. (2002) further noted that women tend to use a greater number of coping behaviors when compared to men. Hence, it appears that there are gender differences as well as similarities in the types of coping strategies used by adolescent boys and girls and that continued research is needed in this area.

\section{Relation between coping styles and physical and psychological health symptoms:}

An important contention of previous studies of adults has been the suggestion that gender differences in both physical and psychological health symptoms may actually be the result of gender differences in coping styles (Fraser, 1986; Hazzard, 1986; Jick \& Mitz, 1985; Myers et al., 1984; Nolen-Hoeksema, 1991; Solomon \& Rothblum, 1986). However, in a looking at adolescent coping strategies and psychosocial health Piko (2001) reported that for Hungarian boys and girls, passive and risk coping factors exerted a negative influence while problemsolving and support seeking strategies played a positive role. As a result, a primary contribution of the present study was to determine whether coping strategy, regardless of gender, correlated to physical and psychological symptoms in adolescents.

For the present study, although the correlations were small in magnitude, we did find that for emotion-focused coping, the correlations between coping and health were positive and were similar for males and females. However, there were a few differences in correlations. Specifically, whereas problem-focused coping correlated positively to vigor in both genders, problem-focused coping was negatively correlated to depression and confusion in females, but positively correlated with tension in males. Regardless of gender, avoidant coping styles correlated positively with physical ailments. Moreover, in females, avoidant coping also correlated positively with certain psychological problems, including anger, tension, depression, and confusion. 


\section{REFERENCES}

Ashton H, Kamali F (1995). Personality, Lifestyle, Alcohol and Drug consumption in a sample $\mathrm{n}$ of British medical students. Med. Educ.29:87-192

Benson H, Stuart EL (1992). The Wellness Book: The comprehensive guide to maintaining health and treating stress-related illness. New York: Carol Publishing Group.

Campbell M, Guthrie E, Block D, Bagalkote H, Shaw C, Creed F (1998). Psychological stress and burnout in medical students : a 5- year prospective longitudinal study J. Roy Soc. Med. 91(5): 237-243.

Carver, C. (1997). You want to measure coping, but your protocol's too long: consider the brief COPE. International Journal of Behavioral Medicine, 4, 92-100.

Cauce, A. M., Paradise, M., Ginzler, J. A., Embry, L., Morgan, C. J., Lohr, Y., \& Theofelis, J. (2000). The characteristics and mental health of homeless adolescents: age and gender differences. Journal of Emotional and Behavioral Disorders, 8, 230-239.

Felsten, G. (1998). Gender and coping: use of distinct strategies and associations with stress and depression. Anxiety, Stress, and Coping, 11, 289-310.

Franken RE (1994). Human Motivation. 3rd ed. Belmont, CA: Brooks/Cole Publishing Company Fraser, G. (1986). Preventive cardiology. New York: Oxford University Press.

Guthrie EA, Black D, Shaw CM, Hamilton J, Creed FH, Tomenson B. (1995). Embarking upon a medical career: psychological morbidity in first year medical students. Med. Educ. 29:337-341

Hazzard, W. (1986). Biological basis of the sex differential in longevity. Journal of the American Geriatrics Society, 34, 455-47S1.

Holmes TH, Rahe RH (1967). The social readjustment rating scale. J. Psychosom. Res. 11:213218.

Houtman, I. (1990). Personal coping resources and sex differences. Personality and Individual Differences, 11, 53-63.

Jick, T., \& Mitz, L. (1985). Sex differences in work stress. Academy of Management Review, 10, 408-420.

Keller, E. F (1991). Gender and science. In: E. Thermey (Ed.) Women’s studies encyclopedia. New York: Peter Beduck, 153-156.

Kohlman, C., Weidener, G., Dotzauer, E., \& Burns, L. (1997). Gender differences in health behavior: The role of avoidant coping. European Review of Applied Psychology, 47, 115-121.

Lazarus, R. S., \& Folkman, S. (1984). Stress, appraisal and coping. New York: Springer.

Linet, M. S., Stewart,W. F., Celentano, D. D., Ziegler, D., \& Sprecher,M. (1989). An epidemiologic study of headache among adolescents and young adults. Journal of the American Academy of Child and Adolescent Psychiatry, 261, 2211-2216.

Miller P, Surtees PG (1991). Psychological symptoms and their course in first year medical students as assessed by the Interval General Health Questionnaire (I-GHQ). Br. J. Psychiatry 159:199-207. 
Mullis, R., \& Chapman, P. (2000). Age, gender, and self-esteem differences in adolescent coping styles. Journal of Social Psychology, 140, 539-542.

Myers, J., Weissman, M., Tischler, G., Holzer, C., Leaf, P., Orvaschel, H., Anthony, J., Boyd, J., Burke, J., Kramer, M., \& Stoltzman, R. (1984). Six-month prevalence of psychiatric disorders in three communities: 1980-1982. Archives of General Psychiatry, 41, 959

Nolen-Hoeksema S (1990). Sex differences in depression. Stanford, CA: Stanford University Press.

Nolen-Hoeksema, S. (1991). Responses to depression and their effects on the duration of depressive episodes. Journal of Abnormal Psychology, 100, 569-582.

Perczek, R., Carver, C. S., Price, A. A., \& Pozo-Kaderman, C. (2000). Coping, mood, and aspects of personality in Spanish translation and evidence of convergence with English versions. Journal of Personality Assessment, 74, 63-87.

Piko, B. (2001). Gender differences and similarities in adolescents' ways of coping. Psychological Record, 51, 223-236.

Pinel JPT (2003). Biopsychology (5th ed). United States of America: Allyn and Bacon

Porter, L. S., \& Stone, A. A. (1995). Are there really gender differences in coping?: a reconsideration of previous data and results from a daily study. Journal of Social and Clinical Psychology, 14(2), 184-202.

Pritchard, M. E., \& McIntosh, D. N. (2003). What predicts psychological outcomes among law students: a longitudinal panel study. Journal of Social Psychology, 143, 727-745.

Pritchard, M. E., \& Wilson, G. (2003). Using emotional and social factors to predict student success. Journal of College Student Development, 44, 18-27.

Ptacek, J., Smith, R., \& Dodge, K. (1994). Gender differences in coping with stress: when stressor and appraisals do not differ. Society for Personality and Social Psychology, 20, 421-430.

Shaikh BT, Kahloon A, Kazmi M, Khalid H, Nawaz K, Khan N (2004). Students, stress and coping strategies: a case of Pakistani medical school. Educ. Health (Abingdon) 17:346353.

Shettima, A. G. (1996). Gender issues in monitoring the environment: The case of rural Nigeria. A paper presented at the 39th Annual Conference of NGA held at the University of Maiduguri, May, 5-6th.

Stang, P. E., \& Osterhaus, J. T. (1993). Impact of migraine in the United States: data from the national health interview survey. Headache, 33, 29-35.

Stone, A. A., \& Neale, J. M. (1984). New measure of daily coping. Development and preliminary results. Journal of Personality and Social Psychology, 46, 892-906.

Tamres, L. K., Janicki, D., \& Helgeson, V. S. (2002). Sex differences in coping behavior: a metanalytic review and an examination of relative coping. Personality \& Social Psychology Review, 6(1), 2-29.

Townsend, C. O. (2002). Perceived stress, coping and dietary fat intake in rural adolescents: gender and ethnic differences. Dissertation Abstracts International: Section B: The Sciences and Engineering, 63, 1052. 
Weissman MM, Bland RC, Canino GJ, Faravelli C, Greenwald S, Hwu HG, Joyce PR, Karam EG, Lee CK, Lellouch J, Lepine JP, Newman SC, Rubio-Stipec M, Wells JE, Wickramaratne PJ, Wittchen H, Yeh EK (1996). Cross-national epidemiology of major depression and bipolar disorder. JAMA 276(4):293-299.

Werner, E. E. (1989). High risk children in young adulthood: a longitudinal study from birth to 32 years. American Journal of Orthopsychiatry, 59, 72-81.

Wheaton, B. (1985). Models for the stress-buffering functions of coping resources. Journal of Health and Social Behavior, 26, 352-364. 